\title{
Cardiovascular autonomic neuropathy in type 2 diabetic patients
}

\author{
1. Endocrinologist - Doctorate Student at the Laboratory of Vascular Biology and Atherosclerosis. - \\ Faculty of medical Sciences (FCM) - State University of Campinas (Unicamp) - Campinas (SP) - Brasil \\ 2. Full Professor - Department of Cardiology - Laboratory of Vascular Biology and Atherosclerosis - FCM - Unicamp - São Paulo (SP) - Brasil
}

http://dx.doi.org/10.1590/1806-9282.65.1.56

\begin{abstract}
SUMMARY
Diabetes is one of the most common chronic pathologies around the world, involving treatment with general clinicians, endocrinologists, cardiologists, ophthalmologists, nephrologists and a multidisciplinary team. Patients with type 2 Diabetes Mellitus (T2DM) can be affected by cardiac autonomic neuropathy, leading to increased mortality and morbidity. In this review, we will present current concepts, clinical features, diagnosis, prognosis, and possible treatment. New drugs recently developed to reduce glycemic level presented a pleiotropic effect of reducing sudden death, suggesting a potential use in patients at risk.
\end{abstract}

KEYWORDS: Diabetes mellitus. Diabetic Neuropathies. Death, sudden.

\section{INTRODUCTION}

Type 2 diabetes mellitus (DM2) has high morbidity and mortality and great socioeconomic impact, having affected 150 million individuals in the year 2000 , with an expectancy of affecting 336 million by 2030'. The diabetic neuropathy, including the cardiovascular autonomic neuropathy (CAN), is a common complication of type 1 and 2 diabetes that leads to high mortality and morbidity ${ }^{2}$.

Patients with a CAN diagnosis have an increased risk of cardiovascular mortality due to acute myocardial infarction and sudden death. ${ }^{3}$ Although CAN is an important milestone in the history of a DM2 patient and its screening is recommended by the American Diabetes Association (ADA) ${ }^{4}$, its present presents high variability in studies. The values found were close to $2.5 \%$ in the Diabetes Control and Complications Trial (DCCT) ${ }^{5}$; in the Oxford
Community Diabetes Study ${ }^{6}$, the prevalence of abnormal results for anatomic tests was of $20.9 \%$ in DM1 patients and 5.8\% in DM2 patients. In the DiaCAN7 study, the CAN prevalence was of $16.8 \%$ in 647 DM1 patients and 22.1\% in 524 DM2 patients. Despite the high heterogeneity in the epidemiological findings, it is known that the prevalence of CAN increases with age, duration of diabetes, and inadequate blood glucose control, and the presence of hepatic steatosis in patients with a DM2 diagnosis of less than a year showed a strong correlation with anatomic lesions ${ }^{8}$. The late stages of CAN are associated to considerable morbidity and an increase in mortality, related to postural hypotension, exercise intolerance, increase in the intraoperative instability, the incidence of silent myocardial infarction and sudden death ${ }^{2}$. 


\section{PATHOGENESIS}

The autonomic innervation is the primary process in charge of controlling rate and performance. It must be capable of changing the rate in response to changes in the microenvironment. In the presence of sustained hyperglycemia, a neuropathic dysfunction sets in, affecting, firstly, the major and distal nerves and, secondly, the proximal nerves. The vagus nerve is the primary mechanism responsible for $75 \%$ of all parasympathetic activity, and it is the most frequently damaged. Thus, the initial manifestations of CAN involve a parasympathetic dysfunction, with an anomalous predominance of the sympathetic system ${ }^{9}$.

The precise mechanisms of cardiovascular autonomic dysfunction are not yet well understood. Hyperglycemia increases protein glycosylation and causes a gradual increase in the advanced glycation end-products (AGEs) in the tissues. The connection of the AGEs with their receptors (Rage) creates a chronic cascade of inflammation and tissue injury, destroying the mechanisms for autonomic control. In parallel, the neural cardiovascular autonomic dysfunction perpetrates the myocardial inflammation and makes the tissue more excitable, thus stimulating the microvascular endothelial dysfunction and interstitial fibrosis ${ }^{10,11}$.

\section{DIAGNOSIS}

\section{Heart Rate Variability (HRV)}

The earliest sign for a CAN diagnosis is the reduction of HRV. The heterogeneity with each heartbeat is regulated by a balance between the sympathetic and parasympathetic activities in response to a basal metabolic rate. In healthy individuals, the HRV is high. The reduction of HRV is linked to the severity and duration of the DM2 $2^{12}$.

For a diagnosis, the American Diabetes Association (ADA) task force recommends the analysis of HRV from the 24-hour Holter results ${ }^{13}$. The HRV indicators are: RR intervals; standard deviations of all normal RR (SDNN) during the recording; square root of the average square of the differences between consecutive RR intervals (RMSSD); and the percentage of NN intervals with a difference of over 50 milliseconds in relation to the previous interval (pNN50). The RMSSD and the pNN50 are associated with a high-frequency potency $(0.15-0.4 \mathrm{~Hz})$ and, thus, to the parasympathetic activity, while the SDNN is cor- related to a low-frequency potency (0.04-0.15 Hz), reflecting the baroreceptor activity, an index of sympathetic and parasympathetic activities ${ }^{3,14}$.

The CAN diagnosis using the 24-hour Holter requires an abnormal result in at least two of the following six parameters: SDNN $<50 \mathrm{~ms}$, RMSSD $<15$ $\mathrm{ms}$, PNN50 $<0.75 \%, \mathrm{LF}<300 \mathrm{~ms}^{2}$, HF $<300 \mathrm{~ms}^{215,16}$.

\section{Ewing Test}

This is the most classic and cheapest method of diagnosis, with a high reproducibility ${ }^{16}$. The CAN must be assessed by five standardized tests - three of them for a parasympathetic evaluation: responses of the heart rate to deep breathing (E/I ratio), to the orthostatic position (30s/15s ratio), and the Valsalva maneuver. The other two tests evaluate the sympathetic function: responses to arterial pressure when rising and handgrip. The results for each test must be 0 if standard; 0.5 if borderline; 1 if abnormal. A score $\geq 2$ classifies the patient as $\mathrm{CAN}+{ }^{\mathbf{1 7}}$.

\section{Heart Rate Turbulence (HRT)}

The Heart Rate Turbulence is a method first described by Schmidt et al. ${ }^{18}$, in 1999. It consists of two analysis: the beginning of the turbulence (TI) and the turbulence slop (ST), both extracted from the 24hour Holter records. It reflects the fluctuations of the rearranging sinus cycle after a single ventricular ectopic beat $(\mathrm{VBP})^{\mathbf{1 8}}$. The TI indicates the initial acceleration of the sinus rhythm, while the ST reflects the late deceleration stage of the sinus rhythm. When the TI is greater than 0 or the ST lower than $2.5 \mathrm{~ms} /$ $\mathrm{RR}$, the diagnosis is of CAN $+{ }^{16}$. The TFC is a phenomenon present in low-risk patients of ischemic heart disease. The absence of this phenomenon indicates a significantly increased risk of sudden death.

\section{CLINICAL CHARACTERISTICS}

\section{Exercise Intolerance}

The autonomic dysfunction can also lead to exercise intolerance with a disproportionate increase in heart rate and arterial pressure during exercise, a reduction of the systolic volume, and slow recovery.

A late finding is a tachycardia at rest: A heart rate of approximately 100 beats per minute per minute (bpm) or more reflects a relative increase in the sympathetic tone, associated, to parasympathetic vagus damage. However, confounding factors, such as anemia, dehydration, and hyperthyroidism, must be 
ruled out. A fixed heart rate that does not respond to exercises of moderate intensity, stress, or sleepiness indicates an almost total cardiac denervation and is an indicator of severe CAN ${ }^{19,20}$.

\section{Postural Hypertension}

Some DM2 patients might present orthostatic hypotension, i.e., a reduction of over $20 \mathrm{mmHg}$ in systolic arterial pressure and $10 \mathrm{mmHg}$ in diastolic arterial pressure when rising. This finding occurs due to sympathetic vasomotor denervation, causing a reduction of the vasoconstriction capacity in the peripheral vascular beds. The symptoms associated with orthostatic hypotension include visual darkening, weakness, and, in more severe cases, syncope when rising. These events may be aggravated by several medications, such as diuretics, vasodilators, and tricyclic antidepressants ${ }^{11,17}$.

Healthy individual present a reduction of the arterial pressure during sleep. CAN patients can present, in the 24-hour map, a low decrease of the nocturnal arterial pressure (lower than 10\%), contributing to left ventricular hypertrophy a fatal and non-fatal cardiac events ${ }^{21}$.

\section{Imaging Exam}

The MIBG (metaiodobenzylguanidine) is a non-metabolized marker, analogous of the norepinephrine, useful for the assessment of post-ganglionic neural fibers. Several studies have shown a decrease in the MIBG uptake in CAN patients. Some studies have shown a higher sensitivity of MIBG when compared with autonomic tests ${ }^{22}$. When CAN is present, the MIBG scintigraphy shows a lower uptake, especially in posterior and inferior segments of the left ventricle, up to the total absence of MIBG capitation in the advanced CAN.

\section{PROGNOSIS}

A meta-analysis with over 2,900 patients showed that mortality for a period of up to ten years was of $30.4 \%$ in diabetic patients with CAN, detected through the reduction of HRV, and $13.4 \%$ in those with no signs of CAN through HRV ${ }^{10}$. Whitsel et al..$^{23}$ demonstrated that patients with a CAN diagnosis presented a significant risk of prolonged QT intervals, which are associated with sudden deaths. This meta-analysis showed 2.3 times increase in the risk of prolonged QT interval in patients with diabetes and CAN.
Another publication of the Diad study showed that the CAN is an important predictor for silent myocardial ischemia, which was found in $22 \%$ of the asymptomatic DM2 patients. In addition, during exercise, diabetes patients with CAN presented a delay in the angina pain, even though the ischemic process was already underway, with a predisposition for prolonged ischemia ${ }^{25}$.

Some trials have suggested that sudden death is the second or first most common cause of death for DM2 patients. As an example, we can mention the subanalysis of the Tecos study, which showed that sudden death was the primary cause of death of cardiovascular origin (27\%), followed by AMI/CVA (21\%), and heart failure $(12 \%)^{26}$. In the Empa-REG study, sudden death was also the leading cause of death with a cardiovascular origin $(29.9 \%)^{27}$. In the Savor-Timi 53 study, $45 \%$ of deaths due to cardiovascular origins were sudden deaths ${ }^{28}$. Thus, CAN must be actively investigated in DM2 patients.

\section{CLASSIFICATION}

The Ewing tests are the golden standard for CAN diagnosis. The reference values change according to age. A single test with alterations already raises the possibility of CAN. Two or more tests with alterations are a definite indicator of CAN. CAN present only after a HRV assessment is named as subclinical, while the presence of orthostatic hypotension implies severe $\mathrm{CAN}^{29}$.

\section{TREATMENT}

The best chance for intervention and changes of prognostics for a CAN patient is the early diagnosis. The treatment is based on non-pharmacological treatments that include weight loss and improvements to insulin resistance, since both are associated with sympathetic hyperactivity, and exercises must be of low to moderate intensity ${ }^{30}$. Pharmacological measures, such as ACE inhibitors and beta-blockers, can contribute to the attenuation of CAN symptoms ${ }^{4,31}$. Therapies whose focus is, exclusively, the action of the sympathetic nervous system still require further studies, such as (i) hyperstimulation of the vagus nerve; (ii) renal sympathetic ablation; (iii) resection of the carotid body; and (iv) electrical stimulation of the baroreceptor.

Two classes of drugs for DM2 treatment, iSGLT2, 
and aGLP-1, have shown a reduction in mortality due to cardiovascular disease using mechanisms not often linked to coronary artery disease. In a non-pre-specified analysis of the Empa-REG ${ }^{27}$, it was suggested that: among patients included in the study who suffered a fatal cardiovascular event, 137 (5.3\%) were in the placebo group, while $90(3.8 \%)$ were being treated with $10 \mathrm{mg} / \mathrm{d}$ empagliflozin and 82 (3.5\%) with $25 \mathrm{mg} / \mathrm{d}$ empagliflozin. Sudden death was the cause of death for 38 patients in the placebo group, 30 in the $10 \mathrm{mg} / \mathrm{d}$ empagliflozin group, and 23 in the 25 $\mathrm{mg} / \mathrm{d}$ empagliflozin group. Thus, sudden death was the cause for $1.6 \%$ of all deaths in the placebo group, against $1.1 \%$ in the group treated with empagliflozin, which represented a reduction of $31.25 \%$ in deaths by sudden death in the empagliflozin group. Studies using animals have demonstrated the action of the iSGLT2 in reducing the sympathetic hyperactivity.

In another sub analysis also not pre-specified in the Leader ${ }^{32}$ study, 278 patients progressed to death in the placebo group, against 219 patients in the treated group. Of these, sudden death was the cause of death for 74 (1.6\%) of patients in the placebo group, against $51(1,1 \%)$ in the liraglutide group, representing a $31.25 \%$ reduction in deaths by sudden death.

Thus, these two classes of drugs, iSGLT2 and aGLP1, are found to be possible attenuators of sudden death, perhaps due to their, at least partial, impact on the autonomic nervous system.

\section{CONCLUSION}

CAN is a frequent and important diagnosis achieved through the screening test recommended by the ADA. Due to its prognostic importance in DM2, the risk of sudden death and myocardial infarction and the possibility of treatment must not be neglected.

\section{RESUMO}

Diabetes é uma das mais frequentes patologias crônicas em todo o mundo, cujo tratamento envolve uma equipe multidisciplinar, médicos generalistas, endocrinologistas, cardiologistas, nefrologistas e oftalmologistas. Pacientes com diabetes mellitus tipo 2(DMT2) podem apresentar neuropatia autonômica cardíaca (NAC), levando a aumento de mortalidade e morbidade. Nesta revisão, apresentaremos atuais conceitos, características clínicas, diagnóstico, prognóstico e possíveis tratamentos. Novas drogas recentemente desenvolvidas para redução de níveis glicêmicos apresentaram efeito pleiotrópico de redução de morte súbita, sugerindo um potencial uso neste perfil de pacientes.

PALAVRAS-CHAVE: Diabetes mellitus. Neuropatias diabéticas. Morte súbita.

\section{REFERENCES}

1. Wild S, Roglic G, Green A, Sicree R, King H. Global prevalence of diabetes: estimates for the year 2000 and projections for 2030. Diabetes Care. 2004;27(5):1047-53.

2. Yun JS, Park YM, Cha SA, Ahn YB, Ko SH. Progression of cardiovascular autonomic neuropathy and cardiovascular disease in type 2 diabetes. Cardiovasc Diabetol. 2018;17(1):109.

3. Benichou T, Pereira B, Mermillod M, Tauveron I, Pfabigan D, Maqdasy S, et al. Heart rate variability in type 2 diabetes mellitus: a systematic review and meta-analysis. PLoS ONE. 2018;13(4):e0195166.

4. Pop-Busui R, Boulton AJ, Feldman EL, Bril V, Freeman R, Malik RA, et al. Diabetic neuropathy: a position statement by the American Diabetes Association. Diabetes Care. 2017;40(1):136-54.

5. The Diabetes Control and Complications Trial Research Group, Group TDC and CTR. The effect of intensive diabetes therapy on the development and progression of neuropathy. The Diabetes Control and Complications Trial Research Group. Ann Intern Med. 1995;122(8):561-8.

6. Neil HA, Thompson AV, Thorogood M, Fowler GH, Mann JI. Diabetes in the elderly: the Oxford Community Diabetes Study. Diabet Med. 1989;6(7):608-13.

7. Ziegler D, Gries FA, Mühlen H, Rathmann W, Spüler M, Lessmann F. Prevalence and clinical correlates of cardiovascular autonomic and peripheral diabetic neuropathy in patients attending diabetes centers. The Diacan Multicenter Study Group. Diabete Metab. 1993;19(1 Pt 2):143-51.

8. Ziegler D, Strom A, Kupriyanova Y, Bierwagen A, Bönhof G), Bódis K, et al. Association of lower cardiovagal tone and baroreflex sensitivity with higher liver fat content early in type 2 diabetes. J Clin Endocrinol Metab.

\section{8;103(3):1130-8}

9. Axelrod $\mathrm{S}$, Lishner M, Oz O, Bernheim I, Ravid M. Spectral analysis of fluctuations in heart rate: an objective evaluation of autonomic nervous control in chronic renal failure. Nephron. 1987;45(3):202-6.

10. Maser RE, Mitchell BD, Vinik Al, Freeman R. The association between cardiovascular autonomic neuropathy and mortality in individuals with diabetes: a meta-analysis. Diabetes Care. 2003;26(6):1895-901.

11. Fisher VL, Tahrani AA. Cardiac autonomic neuropathy in patients with diabetes mellitus: current perspectives. Diabetes Metab Syndr Obes. 2017;10:419-34

12. Gerritsen J, Dekker JM, TenVoorde BJ, Kostense PJ, Heine RJ, Bouter LM, et al. Impaired autonomic function is associated with increased mortality, especially in subjects with diabetes, hypertension, or a history of cardiovascular disease: the Hoorn Study. Diabetes Care. 2001;24(10):1793-8.

13. Task Force of the European Society of Cardiology and the North American Society of Pacing and Electrophysiology. Heart rate variability: Standards of measurement, physiological interpretation and clinical use. Eur Heart ). 1996;17(3):354-81.

14. Otzenberger H, Gronfier C, Simon C, Charloux A, Ehrhart J, Piquard F, et al. Dynamic heart rate variability: a tool for exploring sympathovagal balance continuously during sleep in men. Am J Physiol. 1998;275(3 Pt 2):H946-50.

15. Balcioğlu S, Arslan U, Türkoğlu S, Ozdemir M, Cengel A. Heart rate variability and heart rate turbulence in patients with type 2 diabetes mellitus with versus without cardiac autonomic neuropathy. Am | Cardiol. 2007;100(5):890-3. 
16. Lin K, Wei L, Huang Z, Zeng Q. Combination of Ewing test, heart rate variability, and heart rate turbulence analysis for early diagnosis of diabetic cardiac autonomic neuropathy. Medicine (Baltimore). 2017;96(45):e8296.

17. Spallone V, Bellavere F, Scionti L, Maule S, Quadri R, Bax G, et al. Recommendations for the use of cardiovascular tests in diagnosing diabetic autonomic neuropathy. Nutr Metab Cardiovasc Dis. 2011;21(1):69-78.

18. Schmidt G, Malik M, Barthel P, Schneider R, Ulm K, Rolnitzky L, et al. Heart-rate turbulence after ventricular premature beats as a predictor of mortality after acute myocardial infarction. Lancet. 1999;353(9162):13906.

19. Tesfaye S, Boulton Al, Dyck PI, Freeman R, Horowitz M, Kempler P, et al. Diabetic neuropathies: update on definitions, diagnostic criteria, estimation of severity, and treatments. Diabetes Care. 2010;33(10):2285-93.

20. Vinik Al, Ziegler D. Diabetic cardiovascular autonomic neuropathy. Circulation. 2007;115(3):387-97.

21. Serhiyenko VA, Serhiyenko AA. Cardiac autonomic neuropathy: risk fac tors, diagnosis and treatment. World J Diabetes. 2018;9(1):1-24.

22. Langen KJ, Ziegler D, Weise F, Piolot R, Boy C, Hübinger A, et al. Evaluation of QT interval length, QT dispersion and myocardial m-iodobenzylguanidine uptake in insulin-dependent diabetic patients with and without autonomic neuropathy. Clin Sci (Lond). 1997;93(4):325-33.

23. Whitsel EA, Boyko El, Siscovick DS. Reassessing the role of QT(c) in the diagnosis of autonomic failure among patients with diabetes: a meta-analysis. Diabetes Care. 2000;23(2):241-7.

24. Heller G V, Iskandrian AE, Wittlin SD. Cardiac outcomes after screening for asymptomatic coronary artery disease in patients with type 2 diabetes: the DIAD Study: a randomized controlled trial. Trial. 2010;301(15):1547-55.
25. Ambepityia G, Kopelman PG, Ingram D, Swash M, Mills PG, Timmis AD. Exertional myocardial ischemia in diabetes: a quantitative analysis of anginal perceptual threshold and the influence of autonomic function. I Am Coll Cardiol. 1990;15(1):72-7.

26. Sharma A, Green JB, Dunning A, Lokhnygina Y, Al-Khatib SM, Lopes RD, et al. Causes of death in a contemporary cohort of patients with type 2 diabetes and atherosclerotic cardiovascular disease: insights from the TECOS trial. Diabetes Care. 2017;40(12):1763-70.

27. Zinman B, Wanner C, Lachin IM, Fitchett D, Bluhmki E, Hantel S, et al. Empagliflozin, cardiovascular outcomes, and mortality in type 2 diabetes. N Engl J Med. 2015;373(22):2117-28.

28. Scirica BM, Bhatt DL, Braunwald E, Steg PG, Davidson J, Hirshberg B, et al. Saxagliptin and cardiovascular outcomes in patients with type 2 diabetes mellitus. N Engl J Med. 2013;369(14):1317-26.

29. Bernardi L, Spallone V, Stevens M, Hilsted I, Frontoni S, Pop-Busui R, et al. Methods of investigation for cardiac autonomic dysfunction in human research studies. Diabetes Metab Res Rev. 2011;1-21.

30. Howorka K, Pumprla J, Haber P, Koller-Strametz J, Mondrzyk J, Schabmann A. Effects of physical training on heart rate variability in diabetic patients with various degrees of cardiovascular autonomic neuropathy. Cardiovasc Res. 1997;34(1):206-14.

31. Boulton AJM, Vinik Al, Arezzo JC, Bril V, Feldman EL, Freeman R, et al. Diabetic neuropathies: a statement by the American Diabetes Association. Diabetes Care. 2005;28(4):956-62.

32. Marso SP, Daniels GH, Brown-Frandsen K, Kristensen P, Mann IF, Nauck $\mathrm{MA}$, et al. Liraglutide and cardiovascular outcomes in type 2 diabetes. $\mathrm{N}$ Engl | Med. 2016;375(4):311-22. 